\title{
LITHIUM-ION BATTERIES FOR EXPLOSIVE ATMOSPHERE
}

\author{
Copyright Material PCIC Europe \\ Paper No. PCIC Europe EUR 19_32 \\ Kim Fumagalli \\ Excen S.r.l. \\ Via Marcora 69 - San Donato Mil. \\ Italy \\ Massimiliano Bielli \\ Politecnico di Milano \\ Via la Masa 34 - Milano \\ Italy
}

\author{
Roberto Sebastiano Faranda \\ Politecnico di Milano \\ Via la Masa 34 - Milano \\ Italy
}

\begin{abstract}
The use of electrical energy is growing constant in the world. Lithium-ion batteries have been largely used in these cases, therefore they are studied in the past years, with the aim of improve the level of safety guaranteed during their operation. Anyway, safety issues are still present, and the main topic is to avoid the rise of hazardous events, which may be associated to short circuits, over-charge/over-discharge electric currents and over-heating. These dangerous conditions may lead to exothermic chain reactions inside the storage system, which then may release toxic and/or flammable gases and finally catch fire. These problems have to be verified in several applications and in particular, when Lithium-ion battery are used in Explosive Atmosphere. The goal of this Paper is the evaluation of the most safety type of Lithium technology in order to minimize the possible ignition source in the environment with presence of Explosive Atmosphere. Moreover, the paper analyzes the ability of the Battery Manager System to remove the ignition risk residual evaluating its minimum Safety Integrity Level in order to grant a sufficient reliability.
\end{abstract}

Index Terms — Lithium-ion batteries, Battery Manager System, Safety, Failure Mode, Failure Rate, SIL, ATEX, Hazardous Area, Explosive Atmospheres.

\section{INTRODUCTION}

In recent years, Lithium-ion batteries have seen a great growth of their market share, e.g. in consumer electronics (phones, laptops), hybrid and electric vehicles.

The adoption of lithium-ion batteries in hazardous areas is still today something to be yet explored: thermal instability and the safety issues which may arise in case of failure strongly limit the installation of this technology in potential Ex atmospheres. Anyway, market demand of lithium-ion technology for potentially Ex atmospheres is progressively increasing, aiming to replace lead acid batteries which are today the technology most widely adopted in Ex atmospheres to power Ex electric fork lift trucks and as back-up for Ex stand-alone PV.

Many reasons explain how lithium-ion systems have experienced a great penetration in the market share of electrochemical devices and so it is worth to analyze the driving forces for the development of such technology.

Lithium is the third element of the periodic table, with a small ionic radius and a low molecular weight, which involve lower weights, i.e. with respect to lead acid technology. The high chemical reactivity of lithium leads to high specific energy and energy density, meaning that weights and volumes can be reduced.

One of the most important advantage is that lithium-ion batteries allow partial charges, with the possibility to charge $50 \%$ of the available capacity in just half an hour (30 min). Long life-cycles, almost zero maintenance costs and no gas emissions during operation complete this brief analysis about advantages of lithium-ion batteries.
High investment costs and safety issues are nowadays the most important drawbacks. TABLE I resumes a comparison between lead acid and lithium-ion batteries.

TABLE I

COMPARISON LEAD ACID AND LITHIUM-ION TECHNOLOGY

\begin{tabular}{|c|c|c|}
\hline Characteristic & Lead acid & Lithium-ion \\
\hline Cell voltage [V] & 2 & 3.2 \\
\hline Energy density [Wh/] & $54-95$ & $250-360$ \\
\hline Specific energy [Wh/kg] & $30-40$ & $110-175$ \\
\hline Efficiency [\%] & 75 & 97 \\
\hline Replacement timeframe [y] & $1.5-2$ & $5-7$ \\
\hline Safety valve pressure [bar] & 0.2 & 6 \\
\hline Battery cost [\$/kWh] & 120 & 600 \\
\hline
\end{tabular}

\section{LITHIUM-ION TECHNOLOGIES}

Different lithium-ion technologies are nowadays available on the market, depending on the materials adopted for the manufacturing of the anode and the cathode: the combination of these two electrodes gives rise to the cells itself, which usually takes the name of the material exploited for the cathode element.

Considering the anode, the first material adopted was metal lithium: it is both the most electronegative and the lightest [1] material and so it was characterized by high performances and low weights. However, surface deformation of the lithium plate can occur during charge processes, causing the break of the cell electric separator that could result in an internal short circuit. This limit has brought researchers to adopt a different anode: carbonaceous materials eliminate the possibility of dendritic formation and so they were able to increase thermal stability of lithium-ion cells.

Two different anode materials are nowadays adopted in the market of secondary lithium-ion cells:

- graphite;

- lithium titanate oxide.

Carbon anodes can be based on either natural or synthetic graphite, can have high or low surface area, and can have morphologies ranging from amorphous, spherical, or flaky grain structure. All of these material properties affect the thermal response of the anode under abuse conditions.

Graphite is the most common carbon material which is still today widely exploited in lithium-ion cells $[2,3]$. As a matter of fact, most of lithium-ion cells available on the market are made with a graphitic anode.

Lithium Titanate Oxyde (LTO, chemical composition $\left.\mathrm{Li}_{4} \mathrm{Ti}_{5} \mathrm{O}_{12}\right)$ lithium-ion cells have been recently developed, with the aim to increase thermal stability of the system. As a matter of fact, $\mathrm{Li}_{4} \mathrm{Ti}_{5} \mathrm{O}_{12}$ anode has been proposed as a safe alternative to graphite electrodes. The advantages of using this anode material are: no lithium plating on the anode surface, a lower self-heating with respect to graphite, heat generation at elevated temperature is less than graphite and it can absorb $\mathrm{O}_{2}$ from cathode, thus increasing the cell stability. Even if it is a very promising 
technology, investment costs are still today very high and so it is not largely adopted in the market of secondary batteries [4].

On the other hand, conventional materials adopted for the cathode electrode are transition metal oxides, which can be classified as follows:

- LCO: Lithium Cobalt Oxide $\left(\mathrm{LiCoO}_{2}\right)$;

- LMO: Lithium Manganese Oxide $\left(\mathrm{LiMn}_{2} \mathrm{O}_{4}\right)$;

- LFP: Lithium Iron Phosphate $\left(\mathrm{LiFePO}_{4}\right)$;

- NMC: Lithium Nickel Manganese Cobalt Oxide $\left(\mathrm{LiNi}_{0.33} \mathrm{Mn}_{0.33} \mathrm{Co}_{0.33} \mathrm{O}_{2}\right)$;

- NCA: Lithium Nickel Cobalt Aluminium Oxide ( $\left.\mathrm{LiNi}_{0.8} \mathrm{Co}_{0.15} \mathrm{Al}_{0.05} \mathrm{O}_{2}\right)$.

TABLE II provides a review of the different lithium-ion technologies available on the market: the technology takes its name on the base of the material adopted for the cathode manufacturing, except for the LTO technology, which refer to the anode material [5] and [6].

TABLE II

DIFFERENT LITHIUM-ION TECHNOLOGIES

\begin{tabular}{|c|c|c|c|c|c|c|}
\hline Properties & LCO & LMO & LFP & NMC & NCA & LTO \\
\hline Nominal voltage & 3.8 & 4.1 & 3.2 & 3.7 & 3.6 & 2.4 \\
\hline Life-cycle & $\begin{array}{c}500 \\
- \\
1000\end{array}$ & $\begin{array}{c}1000 \\
- \\
1500\end{array}$ & $\begin{array}{l}2000 \\
- \\
5000\end{array}$ & $\begin{array}{l}2000 \\
- \\
3000\end{array}$ & $\begin{array}{c}1000 \\
- \\
1500\end{array}$ & $\begin{array}{c}3000 \\
- \\
7000\end{array}$ \\
\hline $\begin{array}{l}\text { Specific energy } \\
\text { [Wh/kg] }\end{array}$ & $\begin{array}{l}150 \\
- \\
190\end{array}$ & $\begin{array}{c}100 \\
- \\
140\end{array}$ & $\begin{array}{c}90 \\
- \\
140\end{array}$ & $\begin{array}{l}140 \\
- \\
200\end{array}$ & $\begin{array}{c}200 \\
- \\
250\end{array}$ & $\begin{array}{l}60 \\
- \\
80\end{array}$ \\
\hline $\begin{array}{c}\text { Specific capacity } \\
{[\mathrm{mAh} / \mathrm{g}]}\end{array}$ & 145 & 120 & 150 & 170 & 200 & 175 \\
\hline $\begin{array}{l}\text { Temperature increase } \\
\text { rate for thermal failure } \\
{\left[{ }^{\circ} \mathrm{C} / \mathrm{min}\right]}\end{array}$ & 440 & $\approx 100$ & 21 & $\approx 100$ & 260 & N.A. \\
\hline $\begin{array}{l}\text { Onset temperature for } \\
\text { irreversible thermal } \\
\text { instability }\left[{ }^{\circ} \mathrm{C}\right]\end{array}$ & 140 & 200 & 230 & 180 & 150 & $>260$ \\
\hline Cost [\$/kWh] & 200 & 300 & 500 & 380 & 350 & 1100 \\
\hline
\end{tabular}

The variety of lithium-ion technologies developed in the past and recent years is due to the increasing of the market demand for lithium-ion batteries in different application fields. Each technology has positive and negative characteristics, which have determined a specific final use and purpose. Due to high values of specific energy, LCO has been largely adopted for portable electronics devices, such as mobile phones, tablets and laptops. The life-cycle range implies a calendar life of few years, which is an acceptable value for these applications. Higher durability is provided by LMO technology, which is anyway characterized by lower values of specific energy: thus, this solution is mostly used into power tools and medical devices. The most promising technology from durability point of view is the LFP battery, characterized even by 5000 life cycles. The high thermal stability has initially made this solution an interesting candidate for electric vehicle applications. Anyway, low specific energy is a strong drawback with respect to other chemistries and so their role in electric vehicle field is today reduced to industrial vehicles.

NCA and NMC are the most adopted technologies for e-bikes and automotive electric vehicles, mainly because of the very high values of specific energy and specific power which are key properties to provide proper vehicle performances.

On the other hand, LTO batteries are characterized by low nominal voltage and low performances with respect to the other lithium technologies, and so nowadays, they are mainly adopted for low power and portable devices. The driving force for this technology is the safe use due to its thermal stability, since violent explosions do not occur and the energy release in case of failure is limited. Anyway, the associated costs are nowadays very high (about double than LFP technology, $1100 \$ / \mathrm{kWh}$ ) and so they are mainly competitive for small size and format applications.

\section{FAILURE OF LITHIUM-ION BATTERIES}

Lithium-ion batteries can fail for several reasons. In the following all the lithium-ion battery hazard failure modes are described.

\section{A. Manufacturing defect}

Despite quality control and testing to produce reliable systems, the production process may involve inadequate materials, damages of cell components, inclusion of contaminants and so on. Manufacturing defects are one of the most hazardous causes of failure of a lithium-ion cell because it can be rarely detected during use, neither can the consequences be prevented by means of the control methods applicable during operation.

\section{B. Electrical abuse}

Electrical abuse can be further divided between different mechanisms:

- internal short circuit: short circuit occurs when the positive and the negative poles of an electrochemical cell are directly connected one to each other. Once this process occurs, the electrochemical energy stored in the electrode materials would be spontaneously released, with heat generation. Internal shorts are generally caused by impurities, microscopic metallic particles, dendrites on the active material or damage to the separator. Current literature considers three different levels for internal short circuits: Level I, Level II and Level III. Level I faults imply a low cell self-discharge and no significant heat generation. In Level II faults, internal short circuit is enhanced with a consistent voltage drop and temperature increase. Then, Level III faults lead to runaway heat generation. Fig. 1 provides a graphic representation of the different risk level caused by internal short circuits [7].

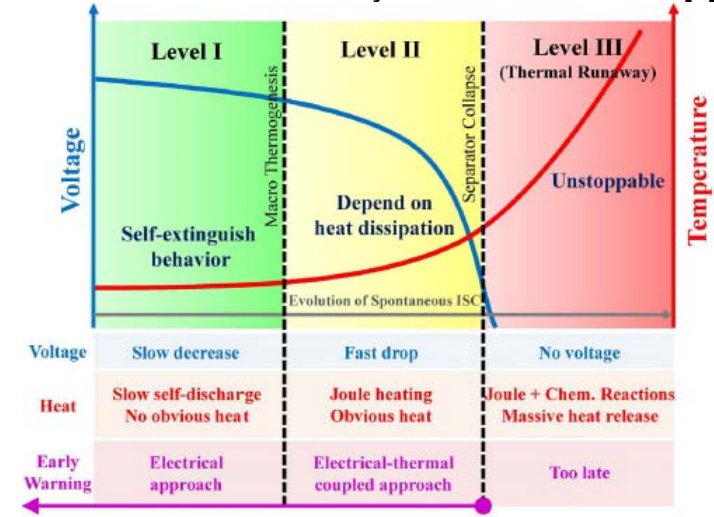

Fig. 1 Three levels of internal short circuit condition

- over-charge (typically higher than $4 \mathrm{~V}$ ): it happens when the cell is charged to a voltage higher than the limit provided by the manufacturer. Over-charge of a lithium-ion cell mainly implies a phenomenon of capacity reduction of the overall system, but, if the maximum charging limit is not properly chosen, lithium-ion cells may be exposed to a continuous temperature increase due to the Joule losses. Both electrodes may be damaged during over-charging: as a matter of fact, side reactions are involved at the anode and cathode elements: first, lithium dendrites grow on the anode surface because of excessive 
lithium "intercalation". On the other hand, the extreme "de-intercalation" at the positive electrode implies the break of the cathode itself, with oxygen release. The failure of the electronic protection system to stop the charging process is the most ordinary source of dangerous conditions;

- over-discharge (typically below 2V): with over-discharge processes, the anode copper current collector may dissolve into the electrolyte. This increases the self discharge rate of the cell. However, as the voltage is increased again above $2 \mathrm{~V}$ (meaning, when the cell is charged again), the copper ions which are dispersed throughout the electrolyte are precipitated as metallic copper wherever they happen to be, not necessarily back on the current collector foil. This is a dangerous situation, which can ultimately cause a short circuit between the electrodes. The cathode is also strongly affected by over-discharge. Keeping the cells for too long periods at voltages below $2 \mathrm{~V}$ results in the gradual breakdown of the cathode with possible oxygen release.

\section{Thermal abuse}

Rechargeable lithium-ion cells are generally allowed to operate within a specific temperature range in order to avoid hazard in case of too high (or low) temperature values:

- high temperature: local overheat occurs as a typical thermal abuse condition in a lithium-ion cell. Overheating processes increase kinetics of chemical reactions and so the power produced by a single cell increases too. This condition may originate from very high ambient temperature, or by an excessive heat production which is not adequately removed by the cooling system, if present. This abuse is more likely for large systems, with the overheating preferentially occurring at the middle of the module;

- low temperature: it hinders the intercalation process of lithium-ions, due to changes in the electrodes material properties. In this way, reaction rates are slower. The consequence of excessive low temperature operating conditions is lithium plating, which cause a reduction in the battery capacity.

\section{Mechanical abuse}

Mechanical abuse generally refers to collision and/or penetration of the storage system due to external effects. In case of hazard collision, the battery pack may deform and two dangerous consequences may result, which are the brake down of the separator (giving rise to internal short circuits) and the leaks of the flammable electrolyte, with potential flames and explosion phenomena.

Penetration is another common hazard that may occur during operation. Violent and instantaneous short circuit may arise due to penetration effects: this condition leads to excessive energy release in less than $60 \mathrm{~s}$, causing a sudden temperature increase. From the mechanical abuse point of view, the structural configuration of the cells plays a significant role, with the pouch cells being the most sensitive to mechanical damages while prismatic design ensures the best mechanical resistance.

\section{E. Ageing}

It is recognized that due to the continuous increase of internal resistance, the performances of the cell (cycle duration, capacity, etc.) continuously deteriorate; at the same time, the cell is more likely to overheating. The cycling volume oscillations of the electrodes (fatigue), due to lithium-ions intercalation during charge and discharge, can also cause the failure of the solid electrolyte interphase, with possible overheating and thermal failure.

Usually, weak abuse operating conditions mainly influences cell performances and life time. Anyway, in case of strong (or continuous in time) hazard, lithium-ion cells undergo thermal runaway phenomena which lead to the explosion of the device.

\section{THERMAL RUNAWAY}

The most dangerous event following a cell failure is thermal runaway, but even in this case, the severity of the consequences depends on a number of factors such as the amount of energy stored in the cell, which in turn is a function of the cell temperature, cell size and characteristics (such as chemistry and mechanical design). Moreover, even the State Of Charge (SoC) strongly affects the amount of heat released during thermal runaway of a damaged cell; different studies and experimental tests have shown that the heat released from a lithium-ion cell subject to abusive operating conditions increases as the SoC percentage increases $[8,9]$. Thermal runaway may result in case of tough abuse of lithium-ion cells. It is based on self-sustained reactions within the cell enclosure, in which the amount of heat generated is higher than the amount dissipated [7]. Thermal runaway involves chain chemical reactions, which are likely to occur one after another. Literature usually splits this feedback process into the following five stages [10].

\section{A. Anodic reaction}

The first phase of thermal runaway is represented by side reactions on the anode material: experimental results have shown that such process is characterized by three different stages [7]. The first stage of the anode degradation process involves decomposition of the Solid Electrolyte Interphase (SEI), which is a protective film on the anode surface. The solid electrolyte interphase is an important component which passivates the active sites of the graphitic anode from possible corrosion, and the electrolyte from reduction. Thus, once a stable layer has been deposited on the anode surface it prevents further electrolyte reduction reactions, while still allowing the intercalation process of $\mathrm{Li}+$ ions into the electrode matrix. SEl formation takes place mainly in the first few charge/discharge cycles, but it continues to stabilize and grow during all the cell life. Fig. 2 shows the protective film (SEI) on the graphitic anode material: it is permeable to lithium-ions, but avoid further solvent reduction reactions.

When the cell is subjected to high stresses, the SEI layer may decompose and successively regenerate. The onset temperature of SEI degradation process strongly depends on the cell SoC. It can be stated that SEI decomposition starts at a temperature which is in the range from $90^{\circ} \mathrm{C}$ to about $140^{\circ} \mathrm{C}$, the higher the $\mathrm{SoC}$ of the cell, the lower would be the initial SEI decomposition temperature $[11,12]$.

Once the SEI breaks, the anode surface has the possibility to come in contact with the solvent of the electrolyte, since the protective layer is no more able to avoid side reactions between the negative electrode and the organic electrolyte. The products of such reaction are the main components of the SEI itself, so that it is regenerated during this second phase of anodic reactions. 


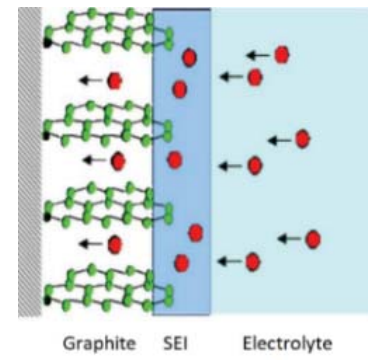

Fig. 2 Graphic representation of SEl layer at the anode

Within the temperature range of $120^{\circ} \mathrm{C}-250^{\circ} \mathrm{C}$, decomposition and regeneration of the solid electrolyte interphase occur at the same time, so that the structure maintains a constant thickness. Anyway, regeneration of the solid electrolyte interphase involves the formation of a non-homogenous (non-uniform) protective layer, characterized by dendrites development, as shown in Fig. 3 [7].

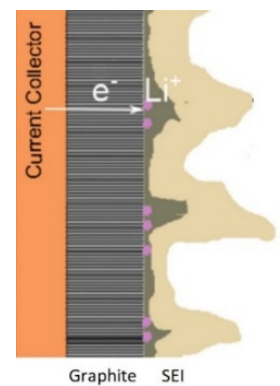

Fig. 3 Dendrites formation on the SEI layer

The last phase regarding anodic side reactions occurs as temperature increase over $250^{\circ} \mathrm{C}$ : in this condition, the graphitic negative electrode structure collapses.

\section{B. Cathodic reaction}

Decomposition of the cathode material strongly depends on the chemistry involved for the lithium-ion cell manufacturing. At high temperatures, the positive electrode can break down and release oxygen, which amount is strongly influenced by the SoC: the higher the cell $\mathrm{SoC}$, the higher would be the oxygen released.

\section{Electrolyte decomposition}

Electrolyte decomposition is a critical phenomenon due to its flammable nature. Both anode and cathode element react with the electrolyte during thermal runaway. Moreover, electrolyte itself decomposes with the formation of gases such as carbon dioxide $\left(\mathrm{CO}_{2}\right)$, carbon monoxide (CO), hydrofluoric acid (HF, which is very dangerous due to its toxicity) and lastly phosphorus oxyfluoride $\left(\mathrm{POF}_{3}\right)$. The cell vents if the internal pressure reaches a limit value (usually 6 bar), allowing these flammable gases to be released to the external environment.

\section{Separator melting}

The fourth stage to be analyzed involves melting of the separator. The melting point for polyethylene and polypropylene are approximately $130^{\circ} \mathrm{C}$ and $170^{\circ} \mathrm{C}$, respectively: researchers have developed separators with ceramic coatings to enhance the collapse temperature to values as high as $200^{\circ} \mathrm{C}-230^{\circ} \mathrm{C}$. The effect of separator melting is a sudden increase of the internal resistance to ion diffusion, as holes in the separator are closed during melting, making it difficult for lithium-ions to be transferred from one side to the other one.

\section{E. Internal short circuit}

The collapse of the separator occurs when the temperature inside the cell is so high that causes the separator vaporization: this condition causes an internal short circuit, with contact between cathode and anode electrodes.

\section{MAIN LITHIUM-ION CELL FAILURE CONDITION}

TABLE III provides a resume of the most important potential failure modes associated to the different cell components. Moreover, a qualitative analysis regarding the probability of occurrence as well as the relative severity is highlighted.

TABLE III

FAILURE CONDITION OF A LITHIUM-ION CELL

\begin{tabular}{|c|c|c|c|}
\hline Cell component & Potential failure mode & $\begin{array}{l}\text { Likelihood of } \\
\text { occurrence }\end{array}$ & $\begin{array}{l}\text { Severity of } \\
\text { occurrence }\end{array}$ \\
\hline Anode & SEl growth & High & Low \\
\hline Anode & SEI decomposition & Moderate & Moderate \\
\hline Anode & $\begin{array}{l}\text { Lithium plating and } \\
\text { dendrite growth }\end{array}$ & Low & High \\
\hline Cathode & Oxygen generation & Low & High \\
\hline Separator & Hole in separator & Low & High \\
\hline $\begin{array}{l}\text { Organic solvent in } \\
\text { the electrolyte }\end{array}$ & Gas generation & Low & High \\
\hline Terminals & Corrosion & High & Moderate \\
\hline Casing & $\begin{array}{l}\text { Short circuit between } \\
\text { positive and negative } \\
\text { electrodes }\end{array}$ & Low & High \\
\hline
\end{tabular}

As already stated, the effects of thermal runaway strongly depend on the materials on which the electrochemical cell is based [13]. Fig. 4 provides the thermal behavior of LCO, NMC and LFP lithium-ion cells subject to heating tests.

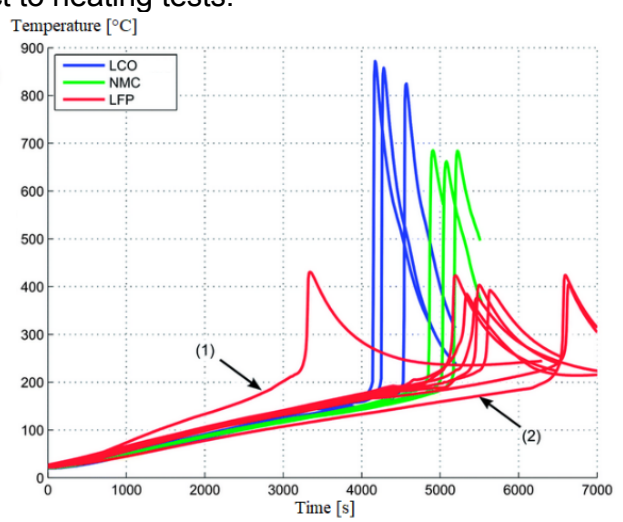

Fig. 4 Temperature trend during heating test and subsequent thermal runaway

To get the results reported in Fig. 4 a continuous heat up process is performed until the lithium-ion cell undergoes thermal runaway. The three chemistries involved in the test are the LCO (blue lines), NMC (green lines) and the LFP (red lines). The measurements have been performed on three test samples for the LCO and NMC cells, while 8 tests have been performed with the LFP cells.

The test samples have been slowly heated starting from $25^{\circ} \mathrm{C}$, with a heat-rate of about $2^{\circ} \mathrm{C} / \mathrm{min}$ (except for line 1 and line 2 of Fig. 4, which are associated to a higher and to a lower heating rate, $3.5^{\circ} \mathrm{C} / \mathrm{min}$ and $1.5^{\circ} \mathrm{C} / \mathrm{min}$, respectively). It is possible to observe that the cell temperature increases with a quite linear trend, until a threshold value is reached (defined as the onset temperature). Then, the temperature profile is characterized by a considerably high and instantaneous growth. The peak in the temperature profile represents 
the maximum cell temperature reached at the end of thermal runaway phenomenon. The onset and the peak temperatures change depending on the chemistry adopted for the manufacturing of the lithium-ion cell, as well as on the cell design and the size of the considered battery pack.

Table IV resumes the most important thermal characteristics of the different lithium-ion technologies available on the market $[14,15]$.

TABLE IV

THERMAL RUNAWAY SPECIFICATION FOR LITHIUM-ION CELLS

\begin{tabular}{|c|c|c|c|c|c|c|}
\hline Properties & LCO & LMO & LFP & NMC & NCA & LTO \\
\hline $\begin{array}{c}\text { Onset temperature for } \\
\text { irreversible thermal } \\
\text { runaway }\left[{ }^{\circ} \mathbf{C}\right]\end{array}$ & 140 & 200 & 230 & 180 & 150 & $>260$ \\
\hline $\begin{array}{c}\text { Temperature increase } \\
\text { rate for thermal failure } \\
{\left[{ }^{\circ} \mathbf{C} / \mathbf{m i n}\right]}\end{array}$ & 440 & $<100$ & 21 & $>100$ & 260 & N.A. \\
\hline $\begin{array}{c}\text { Peak temperature } \\
{\left[{ }^{\circ} \mathbf{C}\right]}\end{array}$ & 870 & 600 & 400 & 700 & 780 & N.A. \\
\hline
\end{tabular}

It is worth considering that, even if the conditions for a thermal runaway are not reached, a number of less severe conditions can still occur in case of abuse operating conditions: the vented gases (produced by a damaged electrolyte) are flammable and in case of ignition can generate a fire; even if not ignited, they are corrosive and can impact on the surrounding items (corrosion, chemical burns to users, etc.).

The important issue of control the lithium-ion cell during service can be satisfied by introducing a protection system, which ensure that the storage system is operated within its safe parameters. For low size lithium-ion cells, the intrinsic safety provided by the cell case is enough to pursuit this purpose, as for example the Pressure, Temperature, Current (PTC) switch and the Current Interrupt Device (CID) for the cylindrical cells. Instead, for large size prismatic lithium-ion cells an electronic control device is required to continuously control and manage the battery, in order to ensure specific safety functions in case of failure or hazard of the battery pack.

\section{BATTERY MANAGEMENT SYSTEM}

Lithium-ion systems are provided with control devices which prevent thermal runaway by keeping the battery within safety voltage and temperature ranges. The Battery Management System (BMS) accomplish the following main goals during the operation of the system: monitoring, protection and balancing.

One of the most important features of the BMS is to control the cell operating parameters by means of sensors and electric inputs. The electronic system is provided with current, voltage and temperature sensors in order to continuously check cell conditions. Based on these inputs, the electric control unit has outputs such as SoC indicator, failure alarm, thermal management module (like fan and electric heater), voltage safety management such as the main circuit contactor. Not all the BMS available on the market are equal: for example, there is not universal standard for the specific number of temperature sensor in a battery pack, even if the optimal solution requires one sensor for each cell. Protection includes switches which are automatically actuated in case of low/over voltage, short circuit or over temperature.

In case of failure, the battery is disconnected from the load: an interface between the user and the battery itself is needed to avoid dangerous situations caused by an unexpected cut-off of the system. Moreover, fuses are used to ensure the system protection even in case of failure of the monitoring system: in case of overcurrent, the fuse breakdown interrupts the circuit avoiding, in this way, an unexpected temperature increase of the lithium-ion cell.

The last important feature of the BMS is to control the SoC of each cell (or a group of cells) managing the charge process by means of external circuits. Balancing of lithium-ion cells is done with the aim of maximize the available capacity of the battery pack. The highest voltage cell will have the highest SoC, while the lowest voltage cell will have the lowest SoC. The highest SoC cell will limit the charging and the lowest SoC cell will limit the discharging, since these cells would reach their maximum and minimum voltage limits before the other electrochemical cells involved in the battery pack: this condition limits the capacity of the overall system leading to lower performances with respect to a balanced cell condition.

Fig. 5 shows a simplified representation of an electrical circuit of a BMS: in the considered example, sixteen lithium-ion cells are connected in series one to each other. It is possible to observe the electric connection between the positive poles of each cell and the control unit of the BMS. The battery pack is protected by a fuse and by switches which are operated in case of hazardous operating condition.

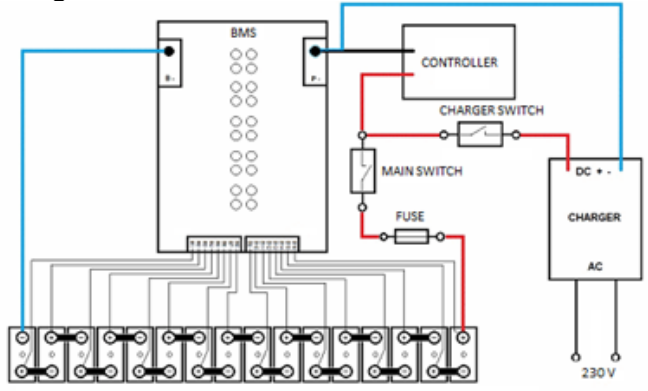

Fig. 5 Simplified electric scheme of the BMS system

\section{EX LITHIUM-ION BATTERIES AND BMS}

ATEX Directives and the IECEx Scheme provide guidelines to ensure safety of electric and non-electric equipment installed in potential Ex atmospheres. They are supported by Technical Regulations in force and family of Standard IEC/EN60079. In particular, Standard IEC/EN60079-0 "Explosive atmosphere - Part 0: Equipment - General requirements" provides a list of primary and secondary batteries which may be used in potential explosive atmospheres, where the lithium-ion batteries are included. Small-size lithium-ion batteries are, for example, used to power portable electronic devices in potentially Ex atmospheres.

The process to Ex lithium-ion batteries design is not trivial: firstly, a deep analysis of the available technologies shall be performed, with the aim to choose the best solution for Ex atmosphere applications. Then, it is required to accurately investigate on the possible failure conditions which may arise during service. The analysis performed in the previous sections provides that the main reason why lithium-ion batteries are so dangerous is that all the components of the fire triangle are found within the electrochemical cell itself (i.e. without requiring an external ambient source of oxygen). Oxygen is available from a damaged cathode, the flammable electrolyte acts as fuel and the high internal temperature may became the ignition source for an explosion phenomenon.

Fig. 6 sum up the hazards of lithium-ion batteries, 
pointing out the ways in which the BMS acts in order to avoid the onset of thermal runaway.

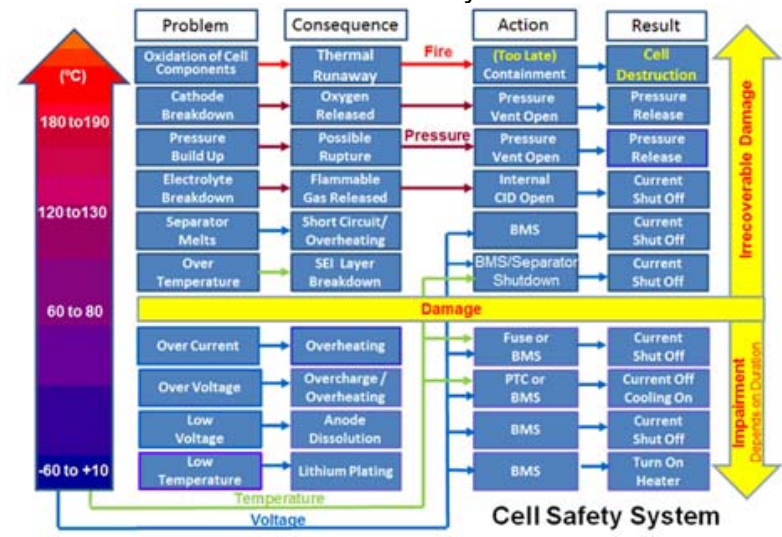

Fig. 6 Safe and hazard operating conditions for lithium-ion batteries

The BMS is a safety device that is used as additional measure to provide protection and prevent ignition even in the occurrence of lithium-ion battery fault. According to the Standard EN 50495, the safety device provides the required protection level by monitoring and acting on detection of a change in the condition of the Equipment Under Control (EUC) [16]. If the EUC is safe only during normal operating conditions, its fault tolerance can be assumed equal to zero, since even a single failure may involve hazard conditions. Thus, the safety device shall be used to ensure the level of safety needed for the specific hazardous area. Table $V$ shows the Safety Integrity Level (SIL) levels used to satisfy the Category of equipment to be installed in Zone 0/20, Zone 1/21 and Zone 2/22 [17,18].

Since lithium-ion systems are safe only during normal operating conditions, the fault tolerance can be assumed equal to zero since even a single fault would imply a hazardous situation. According to TABLE V, a SIL 1 safety device is required for Zone 1/21 application in order for the combined system (lithium-ion battery plus the BMS) to be safe in case of one single fault, while the SIL is not required for safety device when the combined system is installed in Zone 2/22 (only the normal operation has to be considered).

TABLE V

REQUIREMENTS OF SAFETY DEVICES ACCORDING TO SIL QUALIFICATION AND ACCORDING TO THE CATEGORY OF THE EQUIPMENT IN ACCORDANCE WITH THE EXPLOSION PROTECTION REGULATIONS

\begin{tabular}{|c|c|c|c|c|c|c|}
\hline \multirow{3}{*}{$\begin{array}{l}\text { Hazardous Area } \\
\text { EUC } \\
\text { Fault tolerance }\end{array}$} & \multicolumn{3}{|c|}{$\begin{array}{c}\text { Zone } \\
0\end{array}$} & \multicolumn{2}{|c|}{$\begin{array}{c}\text { Zone } \\
1\end{array}$} & \multirow{3}{*}{$\begin{array}{c}\text { Zone } \\
2 \\
0\end{array}$} \\
\hline & \multirow[b]{2}{*}{2} & \multirow[b]{2}{*}{1} & \multirow[b]{2}{*}{0} & & & \\
\hline & & & & 1 & 0 & \\
\hline Safety Device & & & & & & \\
\hline Fault tolerance & - & 0 & 1 & - & 0 & - \\
\hline Safety Integrity Level & - & 1 & 2 & - & 1 & - \\
\hline Combined system & \multirow{2}{*}{\multicolumn{3}{|c|}{$\begin{array}{c}1 \\
0 / 20\end{array}$}} & \multirow{2}{*}{\multicolumn{2}{|c|}{$\begin{array}{c}2 \\
1 / 21\end{array}$}} & \\
\hline $\begin{array}{c}\text { Category } \\
\text { Zone }\end{array}$ & & & & & & $\begin{array}{c}3 \\
2 / 22\end{array}$ \\
\hline \multicolumn{7}{|c|}{$\begin{array}{l}\text { Notes: } \\
\text { "0" states that fault tolerance }=0 \text {, thus safety in guaranteed only during normal operation; } \\
\text { " } 1 \text { " states that fault tolerance }=1 \text {, thus safety in guaranteed with one failure; } \\
\text { "2" states that fault tolerance }=2 \text {, thus safety in guaranteed with two failures; } \\
\text { "-" states that the adoption of a safety device is not required. }\end{array}$} \\
\hline
\end{tabular}

The BMS plays a key role for safe operation of the battery and the effective reliability provided by the BMS itself represents an important limit for evaluation of Ex safety. Moreover, the BMS is not able to protect against all the failure modes described before. In fact, manufacturing defects or mechanical abuse cannot be monitored. They could be considered as a Rare or a Catastrophic malfunction.

Thus, it is necessary to investigate more in depth in order to evaluate the Failure Rate of each Failure Mode. This evaluation is mandatory in order to obtain the safety of the combined system (lithium-ion battery plus BMS) taking into consideration the minimum SIL, according to EN 50495, and the different mode of protection according the family of Standard IEC/EN600079.

\section{PROTECTION METHODS}

To reduce the residual risk ignition of a potentially explosive atmosphere, it is necessary to protect the battery and its BMS with a proper protection method, which provide the protection level for the considered Ex Zone. Being composed of electronics device and relays, the BMS can be protected by flameproof enclosure "Ex d" (IEC/EN60079-1) mode of protection. As previously mentioned, the Intrinsic Safety "Ex i" (IEC/EN60079-11) mode of protection is already used for small sizes of batteries. Among the different protection methods, in case of LFP applications it is possible to consider as the best solution the following protection methods: flameproof enclosure "Ex d" (IEC/EN60079-1), liquid immersion "Ex o" (IEC/EN60079-6) and increased safety "Ex e" (IEC/EN60079-7).

As said before, without an additional investigation about the Failure Rate, it is not possible to confirm the complete safety of the combined system. In the worst case, considering the manufacturing defects or mechanical abuse as an expected malfunction, each mode of protection has some defects, because the BMS cannot fully protect the battery against some failure mechanisms.

Investigating the technical requirements to protect lithium-ion batteries by means of flameproof enclosure "Ex d", it is possible to state that such protection method seems to be feasible both during discharge and charge of lithium-ion batteries. "Ex d" enclosures ensure safety operating conditions in case of failure of the battery, since explosion phenomena are not transmitted to the environment, but they would be confined within the enclosure itself. Anyway, some uncertainties still survive for "Ex d" protection method. For example, it is not quite clear which are the effects of a damaged cell on the external surface of a flameproof enclosure. A sudden and consistent increase of the enclosure surface temperature may imply that the assigned equipment temperature class is exceeded, with the possibility of ignition of a potential explosive atmosphere.

Similar considerations can be made for the mode of protection "Ex o", where, as described in IEC/EN60079-6, the maximum equipment temperature shall be lower than $200^{\circ} \mathrm{C}$ : According to the theory discussed before, this condition would not be satisfied in case of failure of the lithium-ion battery.

In conclusion, also for "Ex e" mode of protection, the scenery does not change. Even if lithium-ion batteries (together with the BMS) satisfy the technical requirements of Standard IEC/EN60079-7, increased safety "Ex e" protection method cannot be considered a suitable solution because in case of failure, flames originating from one or more damaged cells would be directly developed in the hazardous area. Moreover, even if LFP technology represents the safest solution among all the available lithium-ion batteries, the possibility of explosion in case of failure is not precluded and so the protection ensured by "Ex e" method would result not enough since it is not able to contain the explosion phenomena. 


\section{CONCLUSION}

The use of lithium-ion batteries has increased greatly in the past years, gaining growth of their market share. The adoption of this technology for Ex fields is not yet widespread: today only low-size LFP lithium-ion batteries are used to power portable electronic devices for Ex atmospheres because they satisfy the technical requirements for intrinsic safety.

A market analysis of the different lithium-ion technologies available on the market has shown that LTO batter chemistry is the safest solution and so it shall be considered as the reference choice for application in potentially explosive atmospheres. High investment costs and lower performance with respect to the other lithium-ion technologies have strongly limited the market development of LTO batteries: nowadays they are not competitive because the low performance improvement with respect to a lead acid solution would not justify the excessive investment costs. On the other hand, LFP technology provides very good thermal stability and they are characterized by investment costs which are half than LTO solutions: as a matter of fact, today LFP is the most commercialized lithium-ion battery for industrial applications.

This work has been focused on a preliminary analysis about the possibility to use large-size lithium-ion batteries to provide backup power for stand-alone PV systems as well as electric fork lift trucks. From a practical point of view, the replacement of a lead acid battery with a lithium-ion does not involve particular limitations, although weight differences shall be considered in the design of the lithium-ion electric fork lift.

Even if LFP is a safe technology, there are still hazards and so protection methods are needed to ensure safe operating conditions even in presence of explosive atmospheres. The most important limit for the application of LFP lithium-ion batteries in Ex fields is due to the fact that the BMS is not able to protect the battery against all the Failure (manufacturing defects or mechanical abuse). Use in Zone 2/22 seems to be possible for Ex LFP battery, since the probability of formation of an explosive atmosphere is low and the BMS provide a sufficient level of safety during normal operating conditions: thus, it may be possible to classify the battery system as a Category 3 product.

\section{REFERENCES}

[1] A. Eftekhari, "Low voltage anode materials for lithium-ion batteries," Energy Storage Mater., vol. 7, no. December, 2017.

[2] J. Matthey, "Lithium Battery Discussions - Electrode Materials," no. 3, 2016.

[3] F. Vellucci and G. Pede, "Sviluppo di moduli batterie litioioni per avviamento e trazione non automotive," 2011.

[4] D. Doughty and E. P. Roth, "A General Discussion of Li Ion Battery Safety," pp. 37-44, 2018.

[5] K. Higashimoto, H. Homma, Y. Uemura, H. Kawai, S. Saibara, and K. Hironaka, "Automotive lithium-ion batteries," Hitachi Rev., vol. 60, no. 1, 2011.

[6] G. E. Blomgren, "The Development and Future of Lithium Ion Batteries," J. Electrochem. Soc., vol. 164, no. 1, 2017.

[7] X. Feng, M. Ouyang, X. Liu, L. Lu, Y. Xia, and X. He, "Thermal runaway mechanism of lithium ion battery for electric vehicles: A review," Energy Storage Mater., vol. 10, no. December 2016.

[8] E. P. Roth, C. Crafts, D. Doughty, and J. McBreen, "Advanced Technology Development Program for Lithium-Ion Batteries: Thermal Abuse Performance of
18650 Li-lon Cells," Sandia Natl. Lab., no. March, 2004.

[9] C. Di Bari et al., "Procedura di estinzione incendi di celle Litio-ione su scala di laboratorio".

[10] G. Pistoia, "Lithium-Ion Batteries: advances and applications".

[11] M. B. Pinson and M. Z. Bazant, "Theory of SEI Formation in Rechargeable Batteries: Capacity Fade, Accelerated Aging and Lifetime Prediction," J. Electrochem. Soc., vol. 160, no. 2, 2012

[12] "Anode Passivation in Lithium-Ion Batteries", Chidsey Research Group.

[13] A. Kvasha et al., "A comparative study of thermal runaway of commercial lithium ion cells," Energy, vol. 159,2018

[14] U. Osa, I. De Meatza, J. A. Blazquez, H. Macicior, and I. Urdampilleta, "A comparative study of thermal runaway of commercial lithium ion cells sar Guti e," vol. 159, 2018.

[15] B. Lei, W. Zhao, C. Ziebert, N. Uhlmann, M. Rohde, and H. J. Seifert, "Experimental Analysis of Thermal Runaway in 18650 Cylindrical Li-lon Cells Using an Accelerating Rate Calorimeter," pp. 1-14, 2017.

[16] K. Fumagalli, R. Faranda, L. Farnè, "Analysis of possible LED failure mode", AM-14, PCIC 2014, Amsterdam.

[17] K. Fumagalli, M. Martina, P. Corbo, "Light Emitting Diodes (LED) for Installation in Zone 1: A feasible procedure to determine the equivalent protection level", LO-141, PCIC 2015, London.

[18] K. Fumagalli, R. Faranda, P. Corbo, "Different protection modes of Ex LED luminaires", BER-89, PCIC 2016, Berlin.

\section{VITA}

Roberto Sebastiano Faranda received the Ph.D. degree in electrical engineering from the Politecnico di Milano, Milano, Italy, in 1998. He is currently an Associate Professor with the Department of Energy, Politecnico di Milano. His research areas include power electronics, power system harmonics, power quality, power system analysis, smart grids, Ex environment and distributed generation. Dr. Faranda is a member of the Italian Standard Authority; the Italian Electrical, Electronic, Automation, Information, and Telecommunications Federation; and the Italian National Research Council group of Electrical Power Systems. He has authored several papers.

Kim Fumagalli graduated in Electrical Engineering from the University of Politecnico di Milano in 2005. He has obtained the Ph.D. degree in Electrical Engineering at Politecnico di Milano, Milan, Italy, in 2009. He is the Product Certification Manager of Excen S.r.I.. His research areas include LED Source and LED Lighting System, Electrical and Lighting systems for Ex environment, Batteries and Cells, Industrial Trucks and Internal Combustion Engines for Explosive Atmosphere, Ex Products Certification and Testing. He is a member of the IEC Work Group WG40, WG37, MT60079-1, MT60079-14, MT60079-17 and MT60079-19. He is a member of Standards Committee of CEI (Italy) CT31 and SC34D. He has authored several papers.

Massimiliano Bielli graduated in Energy Engineering from the University of Politecnico di Milano in 2018. He is involved in technical-economical feasibility analysis for the installation of cogenerative plants based on internal combustion engines. 